\title{
A ética no montanhismo
}

\section{Mountaineering ethics}

\author{
Edson STRUMINSKI
}

\section{RESUMO}

Imagens sobre montanhas e sobre suas ascensões têm tradicionalmente um forte impacto na sociedade, de tal forma que é praticamente impossível ficar indiferente a estas imagens ou às histórias relacionadas a este assunto. Como se explica isto? Neste trabalho serão apresentadas algumas considerações a respeito da relação que os seres humanos mantém com as montanhas. Para entender esta relação utilizarei o conceito de biofilia. A visão que os humanos tem das montanhas variam bastante conforme a cultura e o período histórico em que vivem, gerando diferentes tipologias biofílicas. Esta visão pode modificar-se também individualmente conforme varie o envolvimento da pessoa com a montanha, de modo que transite de uma tipologia para outra. Para exemplificar este caso, apresentarei as trajetórias de envolvimento de alguns montanhistas com as montanhas. Finalmente, comentarei como estas tipologias biofílicas modificam aspectos éticos presentes no próprio montanhismo para atender a demandas presentes na sociedade circundante.

Palavras-chave: montanhas, montanhismo, biofilia, topofilia.

\begin{abstract}
This paper presents some considerations about the relationship between human being and mountains. It will use the concept of biophilia. The human being's vision about the mountains is associated to the culture and to the historic period. According to the involvement of people with the mountains, the vision modifies itself. It concludes that biophilical typologies modify ethical aspects within mountain's practices to fulfill social demands.

Key-words: mountains, mountain's practice, biophilia, topophilia.
\end{abstract}

\footnotetext{
* Engenheiro Florestal, Mestre em Conservação da Natureza. Discente do curso de Doutorado em Meio Ambiente e Desenvolvimento - Universidade Federal do Paraná. Montanhista. <struminski.e@ig.com.br>
} 


\section{Afinidades humanas com a natureza}

Embora as relações humanas com o mundo natural façam parte tradicionalmente dos escritos produzidos pelas mais diversas civilizações, Tuan (1974, p. 5) foi um dos primeiros autores modernos a utilizar técnicas de percepção para sintetizar as afinidades humanas com a natureza, através de um conceito chamado topofilia, que seria o "elo afetivo entre a pessoa e o lugar ou ambiente físico". Notem que por derivar da geografia, o ente geográfico (lugar) é importante.

Mais recentemente, vindo da biologia e também com base na percepção humana, surgiu o conceito de biofilia, que para Wilson (1984), seria a "idéia da necessidade intrínseca humana do contato com a natureza", o que explicaria a afinidade humana com certos aspectos naturais. Este autor parte de um pressuposto naturalista, segundo o qual a própria natureza explicaria este tipo de necessidade, a qual não poderia ser suprida por versões construídas artificialmente.

QUADRO 1 - TIPOLOGIA DE VALORES BIOFÍLICOS
De acordo com ele, para tornar claro a existência da biofilia, vários autores tem investigado suas formas de expressão através da trajetória humana. Stephen Kellert (1993), conseguiu agrupar em nove tipologias biofílicas estas expressões, adaptadas conforme o quadro a seguir.

De acordo com este quadro, percebemos que a biofilia pode expressar valores individuais ou coletivos. Uma determinada fobia pode ser exclusiva de um indivíduo, assim como a instalação de um novo assentamento humano pode ser movido por percepções estéticas e utilitaristas de um grupo.

Como é relativamente fácil de constatar, a subida de uma montanha sempre muda a perspectiva do ser humano com o seu mundo. De um lado, o esforço físico e mental que a ascensão requer valoriza a pessoa. De outro, a mudança de escala mostra um mundo maior e um ser humano (e suas intervenções na paisagem) mais reduzido. A ascensão de montanhas tem um impacto forte na consolidação de valores biofílicos ou na aquisição de novos valores, conforme veremos a seguir. 


\section{Afinidades humanas com as montanhas}

Para Tuan (1974, p. 80), certos aspectos da natureza desafiam o controle humano fácil. É o caso das montanhas, desertos ou mares, que constituem elementos permanentes no mundo humano, quer se goste ou não. Este autor, afirma que a tendência humana é a de responder emocionalmente a estes aspectos da natureza, tratando-os (no caso das montanhas), dependendo da época, como feios e desagradáveis (a abóbada dos demônios), ou como sublimes, divinos (a abóbada dos deuses). Para ele, em tempos modernos, a carga emocional (visão moralista) anda enfraquecida, porém permanece um forte elemento estético nas atitudes para com as montanhas que não pode ser facilmente influenciado.

Tuan considera ilustrativo o caso da montanha como exemplo na mudança da atitude humana com relação à natureza. A montanha e o vale (alto e baixo; vertical e horizontal), são classificados por ele como um dos muitos pares opostos que a mente humana selecionou na natureza (oposições binárias). No início da história humana a montanha era vista como remota, perigosa e inassimilável (visão negativista) às necessidades do trabalho diário do homem, em contraposição com os vales ou planícies. Povos em diferentes partes do mundo consideravam a montanha como o lugar onde o céu e a terra se encontravam. $\mathrm{O}$ autor cita como exemplos o monte Olimpo na Grécia antiga ou o monte Fuji para os japoneses. Muitas montanhas tem até hoje em seu topo cruzes que simbolizam uma religiosidade extremada (visão moralista).

Tanto nas civilizações ocidentais quanto nas orientais as atitudes para com as montanhas mudaram com o tempo. Inicialmente o temor se combinava com a aversão, posteriormente passou para um sentimento pelo sublime, depois pelo pitoresco e finalmente para a avaliação moderna das montanhas como recursos recreativos (visão naturalista). Na China esta mudança começou a ocorrer já no século 1000 , de acordo com Tuan (1974, p. 82).

Também segundo este autor, no ocidente, até meados do século XVIII era insensível a visão que prevalecia sobre as montanhas. A partir desta época, os poetas da fase romântica começaram a cantar o esplendor das montanhas, que possuiam então uma beleza que era o que mais perto havia na Terra do infinito. A idéia da beleza estética enquadrada dentro do formal e do regular cedia espaço frente à irregularidade e ao aparente caos da natureza.

Tornou-se mais fácil viajar e as montanhas que ficaram mais acessíveis perderam muito da sua aparência proi- bida. A emoção declinou com a familiaridade. A partir desta época cada vez mais pessoas viajavam mesclando propósitos científicos e de lazer. Desenvolveram-se teorias de que o ar leve e a água pura da montanha era bons para a saúde (visão utilitarista), levando à construção de sanatórios, hotéis e facilidades turísticas.

No século XIX, o "século das explorações", muitas montanhas foram escaladas pela primeira vez, "conquistadas" pelo homem, tendência esta que permaneceu até o meio do século XX. Passada esta fase de exploração inicial, as montanhas passaram a ser cada vez mais frequentadas, a ponto de, a partir dos anos 1960 com a constatação geral de que o planeta inteiro sofria o assédio desmedido da ação humana, evidenciar-se também a fragilidade das aparentemente "indestrutíveis " montanhas. Porém, é um fato conhecido que a preocupação com o meio ambiente só tomou vulto devido à crescente degradação ou mesmo ao esgotamento dos recursos naturais. Após a realização de conferências internacionais na década de 1970, a concepção do meio ambiente, até então restrita a aspectos físicos e biológicos, ampliou-se para o meio social, econômico e cultural e para uma interação entre todos estes fatores (SÃO PAULO, 1991), o que representa uma ampliação da visão ecológico-científica da montanha.

O ser humano obrigou-se então a assumir o papel de "protetor" da natureza das montanhas que até então mal conhecia, agindo assim como "proprietário da natureza" em benefício desta; ou então, contraditoriamente, achou que por este motivo tinha direito a utilizar os recursos naturais como bem entendesse, provocando sua degradação e às vezes, o esgotamento (SCHEINER, 1979).

O temor, a religiosidade, o pitoresco, a possibilidade de conquista e do benefício à saúde, além da necessidade de proteção e utilização da natureza são, portanto, sentimentos e sensações que o ser humano carrega hoje de forma mesclada em relação às montanhas e que afloram quando são contempladas paisagens onde estão incluídos elementos montanhosos.

\section{O montanhismo e a mudança do ponto de vista}

O título acima apresenta um duplo sentido: de um lado mostrar como o montanhismo muda o ponto de vista do mundo conforme muda a posição (alto ou baixo; segura ou insegura) do praticante desta atividade; de outro lado demonstrar como as sociedades mudam o montanhismo (ou até mesmo foram mudadas por ele). 
Uma visão acadêmica desta atividade nos é apresentada por Radlinger et al (1987). Segundo ele, montanhismo pode ser entendido por andar ou escalar em terrenos típicos deste esporte (rocha, gelo, etc) com o propósito de efetuar um trabalho pessoal especial que se vê possibilitado mediante treinamento. Por exigir este treino do montanhista, a prática esportiva é a regra, daí subentende-se que trata-se de uma atividade que demanda regularidade e frequência para ser bem sucedida, razão pela qual, Lima (1993), considera que não são todos os que sobem montanha, cumes ou paredes, que são chamados de montanhistas, pois há a necessidade de uma performance regular.

No entanto, Calegari (1975), esclarece que o montanhismo é a projeção concreta de um ideal e não simplesmente uma mescla de atividades atléticas, ou o resultado do aprendizado mecânico de certas técnicas. Para este autor, as vitórias obtidas dentro do montanhismo servem como uma prova de que o montanhista se reconhece como pessoa eficiente e capaz de afirmar sua própria personalidade. Trata-se então, de uma sublimação dos conflitos pessoais. Algo que considera, no entanto, aplicável a qualquer disciplina esportiva, muito embora, em suas pesquisas, tenha percebido um grau menor de agressividade em montanhistas quando comparado, a outros atletas de esportes competitivos. Para alguns montanhistas a atividade teria ainda um forte valor simbólico frente a sociedade à qual pertence, pelo fato de poder em "olhá-la de cima" e superá-la (de onde se origina o termo "alpinismo social"). Assim, se o ideal do montanhista é "vencer o medo", "vencer a montanha" (visão dominionista), conhecer, auto-conhecer-se, cooperar ou outro qualquer, variará conforme a pessoa ou mesmo o momento histórico de uma sociedade.

Entretanto, Krakauer (1999, p. 9) afirma, sem muitos rodeios, que o que leva alguém a escalar é algo que a maioria dos que não fazem parte do mundo dos montanhistas não entende. Para ele, o tema se presta para filmes ruins e metáforas banais, sendo um prato cheio para a interpretação de psicanalistas; a atividade costuma vir associada a histórias de audácia e tragédia que tornam os outros esportes verdadeiros jogos de criança. Ele considera que falar em montanhismo pode provocar no público imagens similares a tubarões ou abelhas assassinas.

Curiosamente, (e talvez por aquele motivo) o montanhismo seduz uma vasta e diversificada fauna de tipos humanos, como se pode deduzir do livro de Krakauer e de outros autores. Este autor, na verdade, nos mostra um retrato nada romântico do montanhismo atual, com tipos gros- seiros, ambiciosos, irresponsáveis muitas vezes e com graus de eficiência muito variáveis nos seus projetos, mas que são atraídos para a escalada pelo aspecto livre e informal da atividade, uma espécie de naturalismo sem compromissos. "Uma das coisas atraentes no esporte era que não importava porcaria nenhuma o que os outros pensassem. Fazer o plano decolar não dependia de conseguir a aprovação de um diretor de pessoal, ou de um comitê de seleção, ou de um grupo de juízes com cara de maus" (KRAKAUER, 1999).

Historicamente considera-se que o montanhismo (alpinismo) iniciou-se com a subida do Mont Blanc, cume alpino mais alto da Europa, em 1786. Trata-se de uma data aleatória, mas importante, em função das mudanças que a sociedade européia vivia com o surgimento de uma burguesia com mais tempo disponível para o lazer, a desacralização da natureza, o cientificismo, o aparecimento de novas máquinas, entre outras mudanças. O montanhismo surgiu assim como uma atividade esportiva que levou aos extremos o rompimento com tendências negativistas da sociedade (medo, aversão), por meio de uma prática esportiva regular, e realçou praticamente todos os demais valores biofílicos humanos que foram explicitados no quadro 1.

A partir da metade do século XIX praticamente todos os países europeus com montanhas importantes (inclusive até mesmo a Inglaterra), já tinham suas sociedades ou clubes de montanhismo atuantes, em outros continentes. Surgiram, então, a literatura e os primeiros periódicos dedicados ao assunto. Também desta época datam as primeiras ascensões importantes nos Alpes (MAZEAUD, 1975, p. 14). Neste momento, o montanhismo foi utilizado dentro e fora do continente europeu por motivos utilitaristas ou científicos (vide a famosa viagem de Humbolt aos Andes) patrocinado por um colonialismo que estava em alta. Ainda assim, muitos montanhistas nutriam individualmente uma visão estética e naturalista bas-tante apurada a respeito da montanha. George Mummery, importante representante deste período declarou que: "o verdadeiro montanhista é aquele que quer chegar onde ninguém esteve antes dele, que sente prazer em tocar as pedras que nenhuma mão havia tocado e a quem seduzem as novas ascensões" (MAZEAUD, 1975, p. 15). Esta concepção avançou até meados da década de 1930 e permanece até hoje. Neste período, entretanto, também havia permanecido uma visão moralista acentuada (lembro aqui que os termos utilizados, como moralismo, utilitarismo, etc, não tem nenhuma conotação pejorativa, servindo meramente como termos classificatórios dos valores biofílicos apresentados no quadro 1). 
Um famoso escalador do período, o francês Lionel Terray comenta que nos seus primeiros anos de montanha, a escalada era "uma espécie de arte religiosa, com tradições, hierarquias e tabus. Dentro desta capela, o racionalismo tinha muito pouco lugar" (TERRAY, 1977, p. 47). Mesmo assim, este autor nos pinta um quadro pessoal em tintas fortes, "a prática apaixonante do alpinismo e a ameaça constante do perigo que nos revolve as entranhas são a origem de fortes emoções morais e religiosas e talvez de elevada espiritualidade" (TERRAY, 1977, p. 35), o que mostra que mesmo para um montanhista inovador como Terray os valores morais deixaram marcas profundas. Enquanto isto, alemães, italianos e austríacos rompiam o pensamento moralista e iniciavam novas modalidades, como a "escalada artificial" em que os meios utilizados pelos escaladores (grampos, mosquetões) eram usados como apoio às ascensões, em contraposição à "escalada livre", em que os mesmos meios eram utilizados exclusivamente para segurança. A escalada instrumentaliza-se e acirra-se, então o espírito de competição, com a realização de escaladas importantes e dramáticas, cujo objetivo era o domínio da montanha e que só seriam repetidas no pós-guerra por Terray e seus companheiros.

Isto só aconteceu porque no início do século XX começa a surgir equipamentos mais especializados para a atividade e o próprio montanhismo se especializaram. Surgem escaladas em rocha, gelo, altas montanhas (acima de 4.000 metros de altitude). O esporte populariza-se e tornase acessível a um número maior de praticantes (MAZEAUD, 1975, p. 16).

No circuito da escalada em rocha surgiu então a concepção de que qualquer parede era expugnável, bastando para tanto aumentar os meios artificiais para seu assalto. Caiu-se então em uma falácia instrumentalista, cujo discurso era "agora estamos vivendo a época das diretíssimas, das alucinantes paredes que saem da vertical" (BISACCIA, 1975), a "rota que um pingo d'água tomaria ao cair da montanha", segundo ouvi dos montanhistas da época. A contradição deste tipo de escalada residia em que, no dizer de um dos seus representantes, "há muitos excelentes escaladores na escalada artificial, que são medíocres na livre" (FRANCESCH, 1975), ou seja, com poucas habilidades para andar livremente na montanha.

Representante da geração anterior, que havia rompido com a rigidez moralista da escalada em rocha, Terray explicitou esta contradição dizendo que o "melhor da escalada livre é a sensação de encontrar-se sem gravidade, subindo sem trava nenhuma", ao passo que para ele " a escalada artificial nos faz sentir exatamente o contrário, movendo-se lentamente e com a ajuda de meios mecânicos" (TERRAY, 1977, p. 127).

Esta primeira fase da escalada artificial teve seu auge durante os anos de 1950, com respingos pelo mundo todo (inclusive no Brasil) até meados da década de 1970. Seus correspondentes no chamado "mundo da Alta Montanha" foram as volumosas expedições que acotovelaram-se no maciço do Himalaia após o fim da Segunda Guerra Mundial. Na verdade, esta região já vinha sofrendo assédio dominio-nístico desde a década de 1920, dentro da política colonial européia, particularmente da inglesa. Durante cerca de 15 anos este país tentou, com todos os meios disponíveis, a ascensão das grandes montanhas da região e, em particular, da mais alta delas, o monte Everest (nome de um militar inglês). As expedições eram aliás organizadas como tarefas militares, envolvendo centenas de pessoas e de recursos. A palavra chave deste período era conquista e só não foi pronunciada devido a limitações tecnológicas que só seriam sanadas após o conflito mundial. De fato, no período entre 1950 e 1960, usando os mesmos meios, o monta-nhismo de Alta Montanha adquiriu tintas nacionalistas e desempenhou o importante papel de elevar a autoestima dos povos recém saídos da guerra. Assim, todas as montanhas acima de 8.000 metros, as mais altas do mundo, foram "conquistadas", pela primeira vez por franceses, ingleses, alemães, italianos, etc.

Nos anos 1960, uma nova geração de jovens nascidos após a 2a Guerra Mundial ingressa no montanhismo e, já não encontra razão nos objetivos traçados pelas gerações anteriores. Inicialmente, estes novos escaladores abandonam totalmente a escalada artificial na rocha. Para eles, inclusive vias clássicas de escalada livre haviam perdido esta característica em função do uso exagerado de meios artificiais. A escalada livre volta a ser um fim graças ao impulso norteamericano no vale do Yosemite e ao europeu nas paredes areníticas do Elba (GSCHWENDTNER, 1986, p. 9). Como já havia acontecido no início do século XX, a escalada desfrutou de inovações nas indústrias têxteis, metalúgica, química, de alimentos, etc. Surgiram novos materiais (notadamente o duralumínio) e equipamentos mais especializados para a atividade, derivados da indústria aeroespacial. Em lugar dos pesados grampos de ferro, que tinham que ser introduzidos à força (marteladas) e danificavam a rocha, surgem variados tipos de cunhas de duralumínio ("nuts", "friends") que se encaixam "amigavelmente" na rocha e, 
principalmente, podem ser retirados ao final sem danos, gerando uma escalada limpa ("clean climbing").

São recuperados valores morais, humanistas e naturalistas, mas principalmente são introduzidos apelos estéticos nas novas escaladas. "Como" escalar passou a ser mais importante em contraposição a "o que" escalar (GSCHWENDTNER, 1986, p. 9). Um representante desta geração, o austríaco Reinhold Messner, causou impacto ao escalar em solo (sozinho e sem corda de segurança) as paredes que se consideravam então as mais difíceis dos Alpes. Convivendo com uma situação que outros escaladores anteriores como Terray já haviam encontrado, declarou: "eu rechaço as hierarquias, em parte porque sei que as posições dogmáticas estão frequentemente em relação inversa à capacidade" (MESSNER, 1995, p. 209). Em função disto e após ficar incapacitado para a escalada em rocha após lesões nos dedos dos pés, acabou também revolucionando o mundo da Alta Montanha ao realizar escaladas vertiginosas na região do Himalaia (foi o primeiro a subir todos os cumes acima de 8.000 metros, sem oxigênio suplementar). Segundo ele, "para um explorador dos limites, é muito mais importante tornar real uma ilusão que figurar no livro Guiness dos recordes" (MESSNER, 1995, p. 115). Messner revela também sentimentos emocionais profundos ao comentar que identifica os deuses com as forças da natureza (moralismo) e, de forma naturalista comenta que os erros na interação entre os homens e a natureza sempre procedem dos seres humanos (MESSNER, 1995, p. 25).

Sem Messner, a escalada em rocha, no entanto continuou avançando e bifurcou-se em caminhos distintos. De um lado, escaladores e escaladoras (as mulheres passam a ter mais autonomia neste terreno) extremos, que buscam realizar vias difíceis em montanhas de difícil acesso, visando a satisfação estética e o contato com a natureza selvagem (naturalismo). De outro os escaladores (e também escaladoras) desportivos, que também buscam realizar vias difíceis, porém com o risco minimizado pelas proteções fixas em montanhas de fácil acesso. Buscam a satisfação estética da atividade atlética, dentro de uma ótica dominionística. Nos anos 1990, a escalada desportiva levou, em alguns casos, a excessos como a colocação de agarras artificiais (resina) em ambientes naturais, ou ao entalhamento (com talhadeira) da rocha para permitir a criação de novas escaladas, o que caracterizou uma nova falácia instrumentalista. Por outro lado, a escalada desportiva desacralizou definitivamente a montanha, urbanizando e abrindo a um público vasto a possibilidade de praticar a escalada, com a criação dos muros artificiais para treinamento e competições que podem ser montados em ambientes fechados (ginásios, garagens). Já a escalada artificial incorporou os novos equipamentos da escalada limpa e tem realizado vias em linhas cada vez mais difíceis sem deixar traços, utilizando valores estéticos e naturalistas.

Nos últimos anos, o montanhismo vem perdendo parte dos seus conteúdos anteriores devido à exposição na mídia ao lado de outros esportes, como surf, skate, paraquedismo, mountain bike etc., que enfatiza os componentes competitivos (dominionísticos) destes chamados "esportes radicais". Recentemente tem surgido competições que são o resultado da combinação destes esportes.

Como seria de se esperar, atividades de ecoturismo incorporam fácil e alegremente muitos elementos presentes no montanhismo. Uma passada de olhos nos programas oferecidos por agências e operadoras permitem identificar estas diferentes visões biofílicas nos "pacotes" turísticos oferecidos com base em viagens pelas montanhas. Aparecem visões dominionísticas ("uma expedição à França lança o desafio para quem deseja chegar aos 4807 do pico Mont Blanc"); estéticas ("paraíso perdido, caminhar pelo leito de riachos que conduzem a cachoeiras de água transparente"), naturalistas ("uma maneira diferente de explorar os canions da Serra Geral é caminhar dentro deles, em vez de andar por sua borda"), entre outras (TERRA, 2000).

Por outro lado, também recentemente (a partir da década de 1990), surgiram vozes dentro do montanhismo reclamando da degradação ambiental nas montanhas. Surgiram novas instituições internacionais como a Wilderness Mountain ou o Fórum das Montanhas, abrigando montanhistas e pesquisadores com a finalidade de proteger os ambientes de montanhas. Esta nova visão ecológico-científica tem se amparado na experiência e no sucesso dos movimentos ambientalistas e nas pesquisas científicas. Por influência desta visão, o presente ano de 2002 foi eleito pela UNESCO como Ano Internacional das Montanhas. Neste ano foram realizadas várias expedições e congressos em prol do ambiente das montanhas e da paz mundial.

\section{Para além do discurso, a ética no montanhismo}

Como seria de se imaginar, a ética no montanhismo está estreitamente ligada à visão biofílica que o praticante da atividade tem. Como foi visto, dificilmente um grupo de escaladores apresenta uma única visão sobre a ativida- 
de. Aliás, historicamente percebe-se que quando uma destas visões é muito predominante caminha-se a passos certos para um situação falaciosa.

Outro dado interessante a se levar em consideração nesta análise é que fala-se muito no meio montanhístico de uma "ética local", que é aquela que usualmente vigora no presente momento em um determinado lugar de escalada (montanha, escola de montanhismo, maciço de montanhas). Assim, um escalador adepto de uma determinada visão da montanha se vê obrigado a respeitar as regras éticas que vigoram nos diferentes locais por onde passar, sob pena de ser execrado. Por outro lado, uma ética local excessivamente fechada pode levar à estagnação da atividade.

Quando estas regras são rompidas surgem atritos e pode-se assistir o fechamento de um grupo em torno da sua ética predominante ou o redirecionamento para a ética da nova visão apresentada. Mess ner é enfático ao afirmar que seu estilo revolucionou o montanhismo e que sua atividade se desenvolve à margem de normas éticas (MESSNER, 1995, p. 23), apenas para afirmar, mais adiante, que seu novo estilo "era mais rápido, elegante, ético" (MESSNER, 1995, p. 26). Esta aparente contradição se explica pelo fato de que este montanhista estava rechaçando uma visão dominionística, com sua ética particular e partindo para outras visões da montanha, onde "o montanhismo de conquista deve desaparecer. Já não tem nenhuma justificativa" (MESSNER, 1995, p. 13). Efetivamente este modo de fazer o montanhismo de Messner (os meios são mais importantes que os fins) influenciou radicalmente os montanhistas que vieram a seguir.

No entanto, outro aspecto importante e complicador a observar é que a partir dos anos 1980 a mídia passa a ter papel importante nas atividades do montanhismo. Assim, parte do estrondoso sucesso que o importante montanhista Messner obteve se deve a financiamentos e patrocínios derivados de sua superexposição na mídia, entidade sabidamente cercada de regras, hierarquias e tabus, portanto com uma ética própria (os fins justificam os meios?). Messner foi autor de diversos livros de aventura, onde difunde seu estilo que mescla valores morais, humanistas, naturalistas e estéticos, juntamente com conceitos que procuram "fazer aplicável à direção de empresas as experiências do alpinismo extremo" (MESSNER, 1995, p. 9). As palavras soam estranhas, mas o fato de um montanhista transitar com desenvoltura na montanha com uma ética e na sociedade com outra poderia ser explicado, então, por tratarse de ambientes diferentes. Para seus (inúmeros) críticos, o montanhista rebate explicando que seu objetivo é estimular a criatividade nas pessoas, e que apesar de pertencer a uma sociedade de bem estar democrática e universal, "eu não funciono somente agregado a esquemas de caráter econômico" (MESSNER, 1995, p. 245).

Montanhista bem sucedido Messner criou escola e seu estilo transpassou para montanhistas de diversos países. No Brasil o conhecido montanhista Waldemar Niclewicz revela também pendores moralistas, naturalistas e estéticos em seus escritos, porém os títulos de alguns de seus livros (Tudo pelo Everest e Diário de uma vitória - a conquista brasileira da montanha mais alta do mundo) revelam sobretudo preocupações dominionísticas que transparecem, como em: "superei o recorde sul-americano de altitude em 500 metros, mas para muitos só a vitória interessa" (NICLEWICZ, 1993, p. 165). Também inserido na mídia, Niclewicz relata que dilemas éticos não chegam a afetar seus objetivos. Instado a enviar uma carta de apresentação da Federação Brasileira de Montanhismo para poder ingressar em uma expedição comercial ao Everest, o montanhista comenta que tal Federação inexiste e portanto "peço desculpas aos partidários da ética esportiva: falsifiquei a carta de recomendação. Bem, tudo pelo Everest!" (NICLEWICZ, 1993, p. 11). Na verdade, como foi visto, dentro dos valores predominantes defendidos pelo montanhista (novamente os fins justificando os meios?) não há efetivamente deslize ético, pois o que importa é a conquista da montanha. Isto pode parecer chocante à primeira vista, mas não deve ser encarado assim. No caso de Niclewicz, seguramente estes valores são ainda bastante comuns e aceitáveis na sociedade circundante, a nossa sociedade aliás, que tem patrocinado seguidamente suas novas viagens. Somente dentro desta ética, Niclewicz pode ser avaliado.

No entanto, um fator complicador é que mesmo montanhistas com visões antagônicas podem eventualmente escalar juntos. Alexandre Portela, importante escalador brasileiro com visão naturalista comenta que para ele "a mais pura e honesta forma de se escalar uma montanha, depois da escalada solo, é fazê-la com seus próprios meios, sem carregadores ou pré equipamento da via" (PORTELA, 2002). Do ponto de vista estritamente discursivo, o fato de que montanhistas com valores naturalistas tenham participado e apoiado Niclewicz em expedições a diversos lugares do mundo deve, portanto, ser explicado por outros motivos, que não suas visões sobre as montanhas explicitadas em seus escritos. Como foi dito, os montanhistas costumeiramente possuem mais de uma visão biofílica so- 
bre a montanha, não sendo portanto totalmente incompatível a reunião de pessoas com diferentes visões no mesmo grupo, muito embora atritos possam surgir. Padilla (2002), agregou vários relatos de ex-companheiros de Niclewicz em uma matéria onde o que transparece são aparentemente conflitos éticos de visões diferentes sobre a escaladas de montanhas.

Evidentemente estes conflitos éticos não são privilégio dos montanhistas nacionais. Além disso, Krakauer (1999, p. 168) nos mostra que o conflito que surge com a interferência da mídia é ainda mais corrosivo do que aparenta à primeira vista. Este autor coletou o depoimento do montanhista Gordon Smith, que teve participação extraordinária em uma expedição inglesa ao Everest em 1982, mas não chegou ao cume. Gordon mostra que durante a caminhada após o fim da expedição os participantes ainda se sentiam muito próximos e amigos. Porém, mais tarde, a mídia começou a separá-los entre "vencedores" (os que chegaram ao cume) e "perdedores" (os que apoiaram os demais). Os vencedores receberam todo o reconhecimento e uma boa quantidade de dinheiro, os demais voltaram para casa sem nenhuma recompensa.

Krakauer (1999, p. 170) constata que "o rumo tomado pelo montanhismo tem sido, na opinião de alguns, injustificadamente imprudente". Para ele,

...o novo modus operandi do montanhismo combinado com a ambição pessoal deixa margem tão pequena para erro que hoje é comum os escaladores iniciarem uma ascensão sabendo que, se algo der errado, o vínculo entre companheiros de corda, um vínculo considerado sacrossanto até recentemente, pode ser abandonado em favor da política do cada um por si.

Para expor e acentuar a polêmica, em 1997 Krakauer já havia escrito o livro "No ar rarefeito", que narra uma tragédia que aconteceu no Everest em 1996, com a morte de 9 participantes de cerca de 30 expedições (um terço delas comerciais). Razel (1998), ressalta que a tragédia em si não bastaria para tornar o livro sucesso mundial de vendas e sim os fatos narrados de forma crua e inédita (para quem não conhece o assunto), tais como: a rivalidade entre as expedições, a falta de experiências dos participantes, a pressão comercial que sofrem os guias (principalmente dos clientes que pagavam entre 20 e 65 mil dólares para chegar ao topo), a falta de companheirismo...
O próprio Krakauer (1999, p. 182) relata uma preocupante estatística que ronda o himalaismo. Segundo ele, do início do montanhismo no Himalaia até 1985, aproximadamente uma de cada trinta pessoas que tentaram escalar um pico de 8 mil metros não saiu com vida. Após esta época este número tem passado, em alguns anos e em algumas montanhas, de uma para cada cinco.

Em uma análise psicológica informal, ele atribui esta estatística, pelo menos parcialmente, à confiança equivocada que muitos escaladores adquiriram após os feitos espetaculares de Messner. Em uma tentativa de competir com ele, muitas pessoas estariam afrontando terrenos perigosos sem o misterioso "senso de montanha", que manteve Messner vivo. De modo geral ele concluiu que as pessoas se arriscam mais porque teriam grandes ambições e muito a ganhar com escaladas espetaculares. Por outro lado, comenta Razel (1998), os equipamentos de montanhismo estão mais leves, resistentes e seguros, derrubando barreiras psicológicas que impediam o acesso de maior número de pessoas a ambientes reservados anteriormente a uma elite de excepcionais montanhistas.

Assim, como diz Razel (1998), o livro de Krakauer sobre o Everest lança uma ducha fria naqueles que acreditavam que o montanhismo fosse uma atividade altamente humana onde reinasse o altruísmo e o companheirismo, e ao mesmo tempo lembra que o Everest (e por extensão as demais montanhas) "foi teatro inesperado da comédia humana. No final das contas, o roteiro é bem dosado entre nobreza e mediocridade, alegria e tristeza, façanha e morte. Sem dúvida outros capítulos serão escritos".

Apesar deste cenário nem sempre agradável, uma visão mais humana do montanhismo não desapareceu. Vejamos a declaração humanista que Filippo Croso, editor da revista brasileira Headwall coletou ao entrevistar os experientes montanhistas Paulo e Helena Coelho, eles próprios protagonizadores de um resgate espetacular no Himalaia: "o que ameaça o montanhismo é o individualismo exacerbado de alguns, que colocam em risco a natureza e a convivência equilibrada entre as pessoas" (CROSO, 2002).

\section{(In)Conclusão}

Sendo montanhista há mais de vinte anos, partilhei de diferentes visões produzidas a respeito dessa prática ao longo do tempo. Muitas delas ainda permanecem comigo quando freqüento as montanhas, razão pela qual não 
foi feito aqui um trabalho sobre ética normativa (que envolveria julgamento de valores dos montanhistas), e sim sobre ética discursiva (apresentação dos diferentes valores). Desta forma, acho difícil falar em "evolução" do pensamento do montanhismo, pois diferentes formas de pensar podem determinar resultados similares na montanha, melhores em um momento, piores em outro principalmente porque na montanha as condições ambientais variam muito e, portanto, fatores subjetivos fazem grande diferença. Por outro lado, por derivar da biologia, a biofilia traz intrínseco o viés evolucionista, o que nos faz pensar intuitivamente em novos valores biofílicos ainda por surgir. Na prática, a atividade do montanhismo continua indo muito bem, obrigado e os feitos das novas gerações continuam acontecendo.

O assunto ética no montanhismo tem sido e será desde sempre, foco de revoluções, discussões, transformações, acomodações, até que um novo ciclo se repita. É um assunto infindável em função das diferentes visões biofílicas que os praticantes desta atividade têm sobre o assunto, como foi visto ao longo deste trabalho. Também parece claro que, principalmente nos últimos anos, estes aspectos éticos tem sido suplantados por ambições pessoais e pela inerente presença da mídia sobre os praticantes da atividade.

\section{Glossário:}

Grampos: Peça metálica em forma de "P", introduzida a marteladas em fendas da rocha (grampos de fenda), ou comprimidos em furos previamente realizados com talhadeira na rocha (grampos de compressão). Em geral não são retirados após o fim da escalada.

Mosquetões: Elo metálico (em geral de ligas leves como o duralumínio) de alta resistência ao impacto, por onde desliza a corda do escalador, servindo para ligar a corda aos elementos de segurança ("nuts", "friends", grampos etc.).
De qualquer modo, se alguma das declarações dos diferentes montanhistas causou impacto em você que leu este artigo foi porque mexeu com suas emoções, com seus próprios valores. Acredito então que este trabalho teve êxito.

Obviamente esta conclusão a respeito das tipologias e dos valores biofílicos e do seu partilhamento simultâneo por diferentes pessoas ou grupos sociais não se aplica exclusivamente ao montanhismo e sim à sociedade como um todo, razão pela qual este trabalho tem sua utilidade como estudo de caso. Poderia-se estar falando de arquitetura de interiores, construção de barragens, educação ambiental, enfim qualquer tema que relacionasse sociedade e natureza.

Também é importante que se diga que o assunto ética não se esgota, naturalmente, com a biofilia. Trata-se apenas de uma ferramenta útil, interessante, que baseia-se na percepção que as pessoas têm da natureza. Neste sentido a geografia, por exemplo, nos apresenta uma ferramenta também interessante, que é a topofilia (TUAN, 1974).

Por representarem visões da natureza estes conceitos permitem a formação de valores, portanto são uma ponte de contato para estudos de ética (filosofia), que foi o exercício aqui realizado.

Neste sentido, agradeço qualquer contribuição para o aprimoramento deste trabalho.
"Nut": Cunhas metálicas (duralumínio, cobre etc.) que encaixa-se nas fendas, podendo-se retirar após o fim da escalada.

"Friend”: Artefato mecânico com molas que exerce pressão sobre as paredes opostas das fendas podendo-se retirar após o fim da escalada.

Agarras artificiais: Peças feitas de resina plástica, moldadas para confecção de apoios utilizados em muros artificiais para treinamento. 


\section{REFER $\hat{E N C I A S}$}

BISACCIA, M. Progresión sobre granito. In: ZOTTO, G. (Org.). Alpinismo moderno. Barcelona: Editorial Hispano Europea, 1975. p. 243-281.

CALEGARI, P. La psicologia del alpinista. In: ZOTTO, G. (Org.). Alpinismo moderno. Barcelona: Editorial Hispano Europea, 1975. p. 31-55.

FRANCESCH, P. La progresión com medios artificiales. In: ZOTTO, G. (Org.). Alpinismo moderno. Barcelona: Editorial Hispano Europea, 1975. p. 283-312.

GSCHWENDTNER, S. Escalada Libre. Barcelona: Ediciones Martínez Roca, 1986.

LIMA, R. O clã da lagartixa, uma visão antropológica da escalada no Paraná. Brasília, 1993. Dissertação (Graduação em Antropologia) - Instituto de Ciências Humanas - Universidade Federal de Brasília. 98 p.

MAZEAUD, P. Evolución histórica y técnica del alpinismo. In: ZOTTO, G. (Org.). Alpinismo moderno. Barcelona: Editorial Hispano Europea, 1975. p. 13-30.

MESSNER, R. Mover montanhas, el credo de un explorador de los límites de lo desconocido. Barcelona: Ediciones Desnivel, 1995.

NICLEWICZ, W. Tudo pelo Everest. Curitiba: Editora Pallotti, 1993.

PÉ na estrada. Os Caminhos Da Terra, ano 6, n. 98, p. 86-89, 2000 .
PADILLA, I. Polêmica nas alturas; as façanhas e habilidades do maior herói do alpinismo brasileiro são contestadas por seus companheiros. Época, São Paulo, p. 80 - 82, 22 jul. 2002.

PORTELA, A. Corazón Caliente, brasileiros na Patagônia. Headwall, São Paulo, ano 1, n. 3, p. 39-45, 2002.

RADLINGER, L.; ISER, W.; ZITTERMANN, H. El entrenamiento en los deportes de montaña. Barcelona: Ediciones Martínez Roca, 1987.

RAZEL, J.C. No ar rarefeito: controvérsia. Outdoor, São Paulo, ano 2, n. 6, p. 50-53, 1998.

SECRETARIA DO MEIO AMBIENTE DE SÃO PAULO (ESTADO). Educação ambiental em unidades de conservação $e$ de produção. São Paulo, 1991. 103 p.

SCHEINER, T.C.M. Sobre turismo e visitação em parques nacionais. Ciências Humanas, Rio de Janeiro, FGV, n. 10, p. 12 20, 1979.

SILVA, M.F. da. Impactos ambientais do ecoturismo: o caso de Bonito - MS. Curitiba, 2002. Tese (Doutorado em Meio Ambiente e Desenvolvimento) - Universidade Federal do Paraná. 202 p.

TERRAY, L. Os conquistadores do inútil. Lisboa: Editorial Verbo, 1977. v. 1.

TUAN, Y. Topofilia: um estudo da percepção, atitudes e valores do meio ambiente. São Paulo: Difel , 1974.

WILSON, E.O. Biophilia. Cambridge, M.A: Harvard University Press, 1984. 